\title{
Keeping the lines open: Exploring communication around nurse education between academia and clinical placement areas
}

\author{
Melissa Holland *1,2 \\ ${ }^{1}$ Pediatrics and PICU, Victoria General Hospital, Victoria, Canada \\ ${ }^{2}$ School of Nursing, University of Victoria, Greater Victoria, Canada
}

Received: November 29, 2014

DOI: $10.5430 /$ jnep.v5n4p90
Accepted: January 23, 2015 Online Published: February 1, 2015

URL: http://dx.doi.org/10.5430/jnep.v5n4p90

\begin{abstract}
It is recognized that there are two significant parts to the process of educating nurses: knowledge acquisition and application. Even as much of the knowledge acquisition has formally transitioned to higher education institutions for many nursing programmes, there is a continued need for strong clinical placements to support application of this knowledge into practice. Competing priorities of service and education can make collaboration a challenge, and communication is frequently noted to be a key factor in developing and sustaining effective partnerships. This study was undertaken to explore how communication around nurse education takes place within the diverse partnerships found within nurse education. Semi-structured interviews were done with participants involved in nurse education from both academic and clinical areas. Using a grounded theory approach, each interview was analyzed, compared and contrasted. This allowed four significant categories to emerge, including Foundation (Purpose and Philosophy), Descriptors (Mode and Form), Variables (Concepts of Lack, Time and Relationship) and Outcomes (Frustration, Ambiguity and Engagement). Communication is recognized as necessary for successful holistic nurse education, and all involved and invested in educating nursing students can recognize the part they can have in addressing personal and systemic communication processes.
\end{abstract}

Key Words: Communication, Academic-service partnership, Nurse education, Clinical education

\section{Introduction}

\subsection{The complexity of nurse education}

Educating nurses is a time and resource intensive undertaking, as the expanding role of nurses has meant increased breadth and depth in nursing theory and research alongside the imperative of developing clinical practice to ensure competent and compassionate nurses.

Many concepts impact how nursing education has evolved and is evolving: where nurse education takes place, how it is undertaken, economic realities, emerging theoretical development and changing philosophies that reflect what is at the core of nursing practice. For there to be any progression towards excellence or expertise in nursing practice within this evolution, there remains the reality that there are two parts to nurse education: knowledge acquisition and the application of this knowledge. ${ }^{[1,2]}$ If these two parts are independently evolving, with no communication between them, there will be a loss realized to both sides as well as to the greater whole. $^{[1,2]}$

\subsection{Transitions in nurse education}

From early times, the need for care has led individuals to devote their time and energies to caring for those who were

*Correspondence: Melissa Holland; Email: melissa.holland@viha.ca; Address: Pediatrics and PICU, Victoria General Hospital, Victoria, Canada. 
unable to care for themselves. Educating the next generation of nurses was often done in a "learn as you go" manner, and while this apprenticeship model was highly successful in ensuring a strong hands-on approach, several societal changes within Western nations pointed to the need for change in the education of a nurse. ${ }^{[3]}$

There was a slow transition to independence for nurse education, moving the responsibility for nursing students from the hospital Matron to the Nursing Instructor, seeking protected time and space for teaching, ${ }^{[4]}$ as well as establishing coursework and fieldwork outside of the hospital.

Even as there were changes, the difficulty of competing priorities of service and education had been recognized. These competing priorities, along with a desire for standardization in nurse education, led to the acceleration of nursing education moving into the domain of higher education. ${ }^{[5]}$

As Gillet ${ }^{[6]}$ notes, some felt this shift of nurse education into higher education would bring greater opportunity for independence with how nursing education developed. However, this has not always become reality as the need for greater collaboration with those in the clinical arena has become increasingly evident.

Despite much planning and effort, there continues to be a gap between theory and practice that can engender conflict and confusion. ${ }^{[7]}$ Some of this can be attributed to the "normal dimensions of human organizational life" of the ideal versus the reality, ${ }^{[8]}$ while other times it can be explained by the lack of support for the nursing student simply from the ambiguity that exists as to with whom the responsibility lies for supporting the student while on their clinical placement. ${ }^{[9]}$

\subsection{Communication as key}

Recorded successes and identified gaps have acknowledged communication as a key factor with partnerships between health and academic institutions in that interactions with clinical staff can both support and hinder students' professional development. ${ }^{[10-12]}$ A true collaborative relationship between partners is "only as effective as the communication between all entities". [13] There is a need for interdependence with all those involved, to acknowledge the imperative of working together towards mutually beneficial goals of excellence in clinical care and education, ${ }^{[7]}$ a commitment that requires discernment and communication of the common values and philosophy. ${ }^{[14]}$

The aim of this study was to explore the communication that takes place around nurse education. The study examines both the perspectives of those who are involved in the academic side of nurse education as well as those who are involved in the clinical side of nurse education.

\section{Methodology}

\subsection{Data collection}

For this project, a qualitative design was chosen using semistructured interviews. Eleven interviews were undertaken over four months with six participants from clinical areas within the South Island region of the Vancouver Island Health Authority and five from Camosun College and the University of Victoria, academic partners in the Baccalaureate of Science in Nursing programme in Victoria, British Columbia. Ethical approval was received from both the health authority and academic institutions. Participants were recruited with an initial letter of invitation, and then purposeful selection was undertaken to ensure there was a variety of areas represented, as well as participants from different levels within the hierarchy of the health authority and the academic institutions.

The interviews took place over a period of four months, with each interview being audio-recorded then transcribed with participant agreement. It was acknowledged and accepted through consent forms that the expected sample size would be relatively small, which could place limits on confidentiality; however, all transcripts identified participants only by number or letter, and any identifying personal or institutional factors were removed.

\subsection{Data analysis}

Following the grounded theory method, also known as the constant comparative method, the initial analysis process was open coding, where the transcripts were analyzed line by line to expose concepts that came to light. Several analytical tools were used in carrying out microanalysis on the context and meaning of words within the text or the newly generated codes. Thought was given to the language itself, considering metaphors, similes and antonyms along with looking at the situations, emotions and the structure of the narrative to seek other possible layers of meaning.

Deeper probing gave insight into the dimensions and properties of the codes; this moved the code beyond a simple label to a whole set of ideas that are captured in the single word or phrase. ${ }^{[15]}$ As comparison was undertaken with coding from previous interviews, axial coding emerged. Memo writing was undertaken around various codes, to gain clarity, defining and redefining the codes, which helped move from simply working with data to generating theory.

There was a continuous process of coming back to the data to examine, compare, contrast, and conceptualize; the research stayed grounded in the data, while theory began to emerge. This emerging theory was examined in light of current literature, acknowledging areas of agreement and places for continued progress.

The final steps of analysis involved further querying, ensuring that the connections in the data were captured through 
the broad categories and sub-themes that had been identified. The categories that had been built up were deconstructed one last time, to ensure that all voices were heard through the data.

\section{Results}

There were four broad categories that arose from the interview data: Foundation, Descriptors, Variables and Outcomes (see Table 1). While there was evident interplay between categories, they each developed their own properties and dimensions, with multiple themes that emerged within each category.

Table 1: Categories and Themes

\begin{tabular}{l}
\hline Foundation \\
• $\quad$ Purpose of Communication Around Nurse Education \\
Descriptors \\
- $\quad$ Mode of Communication \\
- $\quad$ Form of Communication \\
Variables \\
- $\quad$ The Concept of "Lack" \\
- The Concept of "Time" \\
Outcomes \\
- $\quad$ The Concept of "Relationship" \\
- $\quad$ Ambiguity \\
Engagement
\end{tabular}

\subsection{Foundation}

Participants expressed the idea of Foundation often through defining the purpose of their communication. Other times they touched on the broader philosophy, giving understanding to the roots underlying the realities of communication.

Overwhelmingly, most participants saw that a purpose for communication was to clarify. Communication filled the need to share or disseminate information to maintain consistency and meet the needs of multiple groups. At times this was seen in terms of coordinating logistics, but more often it was in terms of communicating essential information, policy, expectations and intentions as well as actual realities of nurse education.

A second widely noted purpose of communication within nurse education was the intent to impact learning through connecting, developing student relationships and supporting practice. However, it was conversely recognized by many that this communication appeared to be problem-driven, as often the initiation of cross-site communication was to address issues and concerns, rather than develop collaboration.

"And so it often comes from a problem that has either taken place from the (academic institution's) perspective or from (the clinical worksite's) perspective that then triggers some communication ..." INTERVIEW A

Beyond purpose, respondents spoke about their personal insights into the philosophy around nurse education as seen in their organization. They understood that this underlying philosophy was often the unspoken motivating factor as to whether communication took place, why it took place and who was responsible for initiating and maintaining the communication.

For both academics and clinicians, there was a pervasive feeling of nurse education being economics-driven. Communication that showed this philosophy included emphasis on budget and investment in growth.

"Um, I would say they value the product that it
produces." INTERVIEW 1
"... which is very difficult because then you are
in this tug of war of constantly trying to fig-
ure out what the true values are of the orga-
nization. So, for example the PPO office, the
professional practice office, values nurse ed-
ucation and promotes nurses' education, and
yet, um ... the finance department or the cap-
ital equipment project process doesn't support
it and that's how we obtain our funding for any
sort of stuff, right?" INTERVIEW 7

However, when considering philosophy there was also mention of vision for best practice that was communicated in a way that inspired academic nurse educators in particular as they saw their work to be all-encompassing of both mind and spirit.

Acknowledgement of shared philosophical attributes did happen, but perceived differences in values were also recognized.

\begin{abstract}
"So there's, it's almost like a lack of respect for each other's perspective or maybe I think what you said was even better, it's just sort of like they prioritize, like they weight the voices differently.” INTERVIEW 8
\end{abstract}

\subsection{Descriptors}

The category of Descriptors reflects the participants' ability to describe the actual tools of communication. Two predominant themes were identified: mode, the mechanism by which communication took place, and form, reflecting the various formats through which mechanical modes of communication could be delivered and received. 
Multiple tools, or modes of communication were noted, some between colleagues, some inter-organizational and some between students. E-mail was overwhelmingly the mode of choice for all organizations. Positively, it was seen as efficient, timely in dealing with issues beyond regular working hours, and allowing for the ability to craft an appropriate response.

"It's always hard to get a lot of people together to communicate in person but e-mail is a pretty good way to do it so that seems yeah, that seems probably the most realistic was of doing it anyways." INTERVIEW 5

However, e-mail was often commented on negatively. It was recognized to be inaccessible on busy days, insufficient to communicate specific types of messages and so overwhelming in number as to render it useless.

"Okay, so e-mail is used predominantly. Most things get really lost on the e-mail. People have you know 800 e-mails coming in within three or four days so e-mail is how things are communicated but it's not really effective." INTERVIEW 6

Several participants noted that they gave significant consideration to the mode of their communication, recognizing it would impact their time in getting information out, as well as impact the reception of the message.

In addition to noting the specific mode to be used, participants also recognized the variability of form they could use. For example, feedback, a common tool to support evaluation of educational process, could be canvassed through a survey, via email, through a written form or face-to-face.

“...whereas when they're more independent the instructor might make a point of asking how they are doing but usually the instructor doesn't, I haven't found that they've engaged very much with me so it's not, it's kind of, it's left up to sometimes like an evaluation form that the student can get their nurse to like fill out and give in, ..." INTERVIEW 1

Form extended beyond format of the communication to also consider the formality or informality of the structure of communication. Participants recognized that there were various factors that would influence how communication was structured.

"And because of our size, we've restructured into more of a hierarchal manner and the program leaders and the chairs frankly make more decisions because that's our job and people who used to be able to participate in that have been excluded from that process and feel that's not, that's not a good thing, but it's hard to know how else we would do that given our size now." INTERVIEW 3

Finally, communication that was neither verbal nor written was also commented on, specifically in the context of instructor presence. From the clinical perspective, having an instructor they 'knew' or who 'was familiar with the unit' demonstrated ability for ongoing dialogue between nurse educator and clinical mentor. In contrast, it was recognized when there was not an effort by instructors to gain familiarity within an area.

\subsection{Variables}

This category encompassed three unique themes: Lack, Time and Relationship, each signifying a variable that impacted the perceived success of communication around nurse education.

The concept of Lack was broad, as participants referred to themselves and others lacking in knowledge and experience around nurse education, communication skills and clinical skills. They also noted lack in specific information around clinical concepts, student levels and necessary contact information. In addition, there was a lack of information around process, with minimal orientation and updates or changes not being communicated.

"There was a new (academic institution) in-
structor that communicated with (the manager)
who didn't really pass things along, and so we
had students arrive on the unit with no orien-
tation to the unit, no preparation and we didn't
even know they were coming." INTERVIEW B

Closely related to the lack of information was the lack of clarity. Information may have in fact been given, but done in such a way that the information was not clear. For many, it was noted that the clarity was never resolved as there was a lack of follow-through as well. And finally, the other significant lack that was perceived was that of consistency.

"If I wanted to provide any feedback I guess I would just have to know when they were there, when the instructor was there and I had the opportunity to speak face-to-face. They usually do at the beginning of the semester... do they usually? Oh dear I can't remember if they actually give us information on who the instructors are. Not anything consistently if they do. It's, I think it's a case-by-case." INTERVIEW 2 
The concept of Time was clearly identified by participants as impacting the ability to have adequate communication. This was seen as a variable with both written and verbal communication. It was recognized that nurse education took time, and figuring out how you needed and wanted to make use of the time you had meant that nurse education was not always the priority.

"Probably a bit associated to time. When you are an instructor of eight students it's splitting yourself in eight different ways and also on the ward staff end of things, you want a coffee break, you don't want a conversation with the instructor, ..." INTERVIEW 2

The final variable that emerged was the idea of Relationship. Participants' concept of how they communicated with academic or clinical colleagues was significantly couched in terms of how they related with those they made contact with inter-organizationally. The variable of relationship was infrequently perceived as neutral, as it elicited a very personal response from participants.

"I just feel ownership over this area. I feel loyalty and, and I'm used to this unit, so I can advocate for this unit when we go to placement meetings and things. So I think that having a instructor that's assigned to the unit for a number of years is helpful and those personal relationships are very important.” INTERVIEW 6

\subsection{Outcomes}

The last overarching category that emerged was Outcomes: participants' impressions and actions as a result of their perception of the communication process. Three themes became apparent in this category: Frustration, Ambiguity and Engagement.

When communication relating to nurse education did not happen effectively, it was apparent there were feelings of frustration. This was particularly evident when trying to improve and attempts were made to communicate, but were not heard or responded to.

"I think you get frustrated when you're always asked something and then they do the exact opposite or whatever information you've provided is just shelved or put into a file, well then, what's the point?" INTERVIEW 9

Some of the frustration was noted from a place of physical exhaustion. Being tired, overwhelmed and 'over-maxed' often meant communication was not given careful consideration before taking place. Reactive communication would result with complaining, using an inappropriate tone when conversing, being rude or placing blame on someone else.

Some clinicians recognized that frustration arose for them when the lack of communication led to a feeling of being imposed upon or taken advantage of. Clinicians and academics alike noted increased frustration arising from a workload that included too many students.

Frustration did not just appear in the moment, however, as many participants also noted longer-term effects such as a consistent negative pattern of communication, passive resistance and exclusion.

The second theme, Ambiguity, became evident when interviewees from both the academic and clinical area noted feelings of confusion, uncertainty, and unknowns. This was very clear when asked specifically to define their understanding of communication around nurse education as they currently understood it.

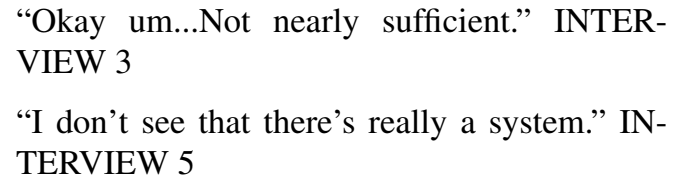

One respondent noted she felt uncomfortable admitting to the unknowns, to what she did not know about nurse education, because she had been working with students for several years. Participants also commented on not understanding each other's roles. Lack of awareness and understanding was seen by one clinician as feeling separated from the process, despite being the nurse who was "hands-on" mentoring a student.

This lack of awareness and assumptions led other participants to recognize inappropriate expectations and an inability to maintain trust.

“... and then I also don't know to say who I can rely on and who I can't. Not that it gets your back up but it puts you on guard all the time." INTERVIEW 4

Many simply noted the weight of not knowing either the expectations or the process. It created more work for them, as they tried to work around the gaps in communication.

When communication was noted to be adequate or improving, there was a significantly different outcome shared by interviewees: Engagement. Communication that worked was noted to be open, transparent and honest. It was a dialogue with an ongoing, consistent two-way flow, and listening was as much a part of the communication as talking. Listening meant others had a voice, and it was a place where others were truly heard. 
“Like you can't be defensive, I think you really have to hear what other people say, so if other people say, this isn't what we need, you know this is what we need, at least be able to engage in some sort of dialogue about it." INTERVIEW 8

There was a clear feeling of unity, both of purpose and in process. Their roles were clarified and they spoke the same language. This led to efforts around nurse education that were coordinated and organized. Challenges around nurse education were still present but participants felt they could recognize the challenges openly, could identify solutions and support colleagues' commitment to improvement.

"Just that I think, I think that it's always it's always worth on all of our parts making the effort to communicate better. And it's always worth if you've had something communicated to you that you think is about a problem or an issue it's always worth going back to the individual and clarifying you know this felt like we were doing something wrong but can you talk more about that and do I have it right." INTERVIEW 3

\section{Discussion}

Communication is noted to be the study of human interaction, ${ }^{[16]}$ defined as a process of information exchange using common symbols or behavior. This study explored that process of communication as it applied to academics and clinicians, both of whom are invested and involved in nurse education.

\subsection{Gaps and successes}

The four broad categories that emerged from participants' interviews explored each step of the communication process. Respondents were able to identify how they saw nurse education valued in their organizations, and were also perceptive in noting dissonance both intra-organizationally and inter-organizationally when expectations were not communicated with clarity, and therefore, were not followed through.

Participants recognized there were specific needs, motivations and values that served as the Foundation from which communication arose. Organizations prioritize based on their values, and differing values will lead to differing actions. Communicating those values in such a way that promotes collaboration and action requires there to be trust between partners. ${ }^{[10,17]}$ O'Neil and Krauel ${ }^{[18]}$ saw this as creating something new: both sides being willing to let go and forge a new entity of what nurse education could be. The authors also note that when partnerships are formed without a clear understanding communicated, an environment is created which is difficult to sustain and be successful.

Discussion around Descriptors of communication was often done as a simple listing of modes of communication, but quickly became a weighted perception of the effectiveness of those tools. The needs of specific situations were recognized as warranting appropriate forms of communication, which participants from both areas acknowledged was often lacking, while also recognizing their own personal responsibility to put forethought and consideration into the communication they were responsible for.

Of significant insight was the repeated recognition of communication that was neither verbal nor written, and how this "unspoken" communication in fact communicated volumes. Karshmer $^{[19]}$ argued that with these unspoken and therefore unmet expectations, neither academics nor clinicians are able to participate fully in the collaboration needed for successful nurse education.

Variables were perceived by interviewees as the constructs that most directly and consistently impacted their ability to communicate. Often beyond individual control, the unique aspect that emerged was that participants' perception of these variables could exacerbate or mitigate the weight of the variables.

This certainly leads to the question, "Can one's perception be changed?" That may be difficult to answer, as despite the objective fact of specific variables, the perceptions noted by participants are often coming from a very personal view of that objective data.

For example, if unable to contact an instructor because no contact information has been made available in the clinical area, that objective fact is seen as a lack of information. If no effort is made to find the information, the objective fact has become a barrier. However, if that lack is recognized, and one is immediately aware of alternate avenues to gain that contact information, the lack does not become a barrier but merely a minor impediment as one recognizes ways to continue communicating. In fact, seeking out a variety of avenues could lead to a broader network of communication, which would be seen as a success.

MacIntyre et al. ${ }^{[20]}$ identified strategies for addressing partnership dynamics that identified use of the words "reenvision" and "re-conceptualize"; to truly address such issues, they had to be seen in a different light.

Looking at Outcomes meant a careful consideration of the impact that communication has on every aspect of nurse education. Certainly some of these outcomes could come with a financial tag attached that would give a precise definition of the cost of lost hours, resources and opportunities that have resulted from communication issues, and equally the increased productivity and resources gained from effective 
communication. However, that would simply be considering a monetary value. The real story from these outcomes that emerged is the potential for what could have been for nurse education. Outcomes of frustration and ambiguity do not lead to progress; rather, they perpetuate a cycle of perceived inadequacy and actual ineffectiveness. Engagement, while acknowledging the true issues, allows for a sense of hope with a commitment to broader understanding and better practice.

It is interesting to note that all participants interviewed were able to see clearly the outcomes of negative and positive communication patterns. This indicates to the researcher that there is alignment or common ground to build on. As readily seen in the literature, acknowledging that alignment allows colleagues from both areas to work collaboratively to make changes. ${ }^{[11,12,21]}$

\subsection{Limitations of the study}

This study was done as an exploratory study to examine current communication patterns within nurse education, and was therefore limited to a single nursing programme with clinical areas focused in one regional area. While the results may not be immediately generalizable to all programmes involved in nurse education, the findings may be a starting point to examine where gaps and successes in communication are present in other programmes, and how they are being addressed. Additionally, to those who are involved in nurse education, it can serve as a reminder to consider their personal involvement in each aspect of communication with forethought and care.

\section{Conclusion}

Communication is a construct that is incredibly complex when it is between humans, and even more so when trying to decipher it on an organizational level. However, it is a personal construct, and as the results of this study show, many participants considered what their personal responsibility was, both for their own communication, as well as for their part in the broader systemic communication that happens around nurse education. As many participants voiced, this could mean a consideration of changes in clinical or academic positions to enable more thoughtful, thorough and efficient communication.

While it is not a simple problem with a single solution, it evidently impacts all those involved with nurse education, and is therefore an important area to continue to examine and improve.

\section{Conflicts of Interest Disclosure}

The author declares that there is no conflict of interest statement.

\section{References}

[1] McHugh MD, Lake ET. Understanding Clinical expertise: nurse education, experience and the hospital context. Research in Nursing and Health. 2010 Aug; 33(4):276-287. PMid:20645420 http: //dx.doi.org/10.1002/nur. 20388

[2] Benner P. From novice to expert. American Journal of Nursing. 1982 Mar; 82(3): 402-407. PMid:6917683

[3] Canadian Nurses Association. Entry to the practice of nursing: a background paper. Ottawa: Canadian Nurses Association; 1982; 35.

[4] Pearson A. The Royal Jubilee School of Nursing 1891 - 1982. Victoria: The Alumnae Association of the Royal Jubilee School of Nursing; 1985; 203. PMid:2983602

[5] Petit dit Dariel O, Waelli M, Rickets TC. France's transition to academic nursing: the theory-practice gap. 2014 Oct; 4(10): 88-100.

[6] Gillett K. From 'part of' to 'partnership': the changing relationship between nurse education and the National Health Service. Nursing Inquiry. 2010 Sep; 17(3): 197-207. PMid:20712658 http: //dx.doi.org/10.1111/j.1440-1800.2010.00496.x

[7] Mannix J, Wilkes L, Luck L. Key stakeholders in clinical learning and teaching in Bachelor of Nursing programs: a discussion paper. Contemporary Nurse. 2009 Apr-Jun; 32(1-2): 5968. PMid:19697978 http://dx.doi.org/10.5172/conu.32.1 $-2.59$

[8] Ralph E, Walker K, Wimmer R. Practicum and clinical experiences: postpracticum students' views. Journal of Nursing Education. 2009 Aug; 48(8): 434-40. PMid:19681532 http://dx.doi.org/10. 3928/01484834-20090518-02

[9] Henderson A, Twentyman M, Eaton E, Creedy D, Stapleton P, Lloyd B. Creating supportive clinical learning environments: an intervention study. Journal Of Clinical Nursing. 2010; 19(1-2): 177-182.
PMid:19686319 http://dx.doi.org/10.1111/j.1365-2702. 2009. 02841 . $x$

[10] Plowfield L, Wheeler E, Raymond J. Time, tact, talent and trust: essential ingredients of effective academic-community partnerships. Nursing Education Perspectives. 2005 July; 26(4): 217-220. PMid:16175911

[11] Teel C, MacIntyre R, Murray T, Rock K. Common Themes in Clinical Education Partnerships. Journal Of Nursing Education. 2011 July; 50(7): 365-372. PMid:21534501 http://dx.doi.org/10. 3928/01484834-20110429-01

[12] Breslin E, Stefl M, Yarbrough S, Frazor D, Bullard K, Light K, et al. Creating and sustaining academic-practice partnerships: lessons learned. Journal of Professional Nursing. 2011 Nov-Dec: 27(6): e33-e40. PMid:22142924 http://dx.doi.org/10.1016/j.pro fnurs. 2011.08 .008

[13] Kinnaman ML, Bleich MR. Collaboration: aligning resources to create and sustain partnerships. Journal of Professional Nursing. 2004 Sept-Oct; 20(5): 310-322. PMid:15494965 http://dx.doi . org/10.1016/j.profnurs. 2004.07.009

[14] Campbell S, Lloyd H. Shared interests. Nursing Management -UK. 2005 Nov; 12(7): 28-30.

[15] Corbin J, Strauss A. Basics of qualitative research: techniques and procedures for developing grounded theory. 3rd ed. Thousand Oaks (CA): Sage Publications Inc.; 2008; 379.

[16] Mortensen CD. Communication: the study of human interaction. New York: McGraw-Hill Book Company; 1972; 430.

[17] Barger SE, Das E. An academic-service partnership: ideas that work. Journal of Professional Nursing. 2004 Mar-Apr; 20(2): 97-102. PMid:15176011 http://dx.doi.org/10.1016/j.pro fnurs.2004.02.005 
[18] O’Neil E, Krauel P. Building transformational partnerships in nursing. Journal of Professional Nursing. 2004; 20(5): 295299. PMid:15494962 http://dx.doi.org/10.1016/j.profn urs. 2004.07.006

[19] Karshmer JF. Leadership for academic-service partnerships: a mandate for the profession. Nurse Leader. 2010 Apr; (8)2: 52-55. http://dx.doi.org/10.1016/j.mnl.2010.01.006

[20] MacIntyre RC, Murray TA, Teel CS, Karshmer JF. Five recom- mendations for pre-licensure clinical nursing education. Journal of Nursing Education. 2009 August; 48(8): 447-453. PMid:19681534 http://dx.doi.org/10.3928/01484834-20090717-03

[21] Nabavi FH, Vanaki S, Mohammadi E. Systematic review: process of forming academic service partnerships to reform clinical education. Western Journal of Nursing Research. 2011 Jan; 34(1): 118-141. PMid:21282459 http://dx.doi.org/10.1177/01939 45910394380 